\title{
C-reactive Protein Versus Erythrocyte Sedimentation Rate in Estimating the 28-joint Disease Activity Score
}

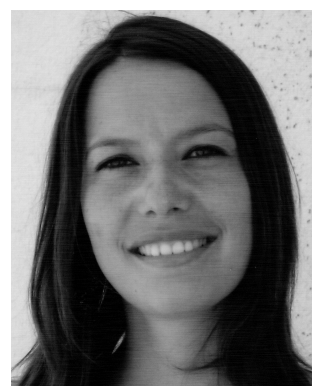

The management of rheumatoid arthritis (RA) has changed radically over the last 15 years, with the introduction of new drugs and treatment strategies and with the emergence of new concepts of disease severity, treatment targets, and means of evaluating treatment effects.

In particular, the necessity to evaluate disease activity using an objective and accurate instrument has been demonstrated. In clinical practice, the 28-joint Disease Activity Score (DAS28) has gained widespread use in the monitoring of disease activity of patients with RA treated with synthetic and biological disease modifying antirheumatic drugs ${ }^{1}$. There is, however, no consensus on the optimal DAS version to be used. DAS28-CRP (C-reactive protein) was developed as a modification of DAS28-ESR (erythrocyte sedimentation rate), which had also previously been developed as a modification of the original $\mathrm{DAS}^{2}$.

Using CRP for calculation of the DAS28 is an attractive alternative to ESR for several reasons. First, CRP is very sensitive to short-term changes in inflammation ${ }^{3}$. Second, CRP is more accurate as an indicator of inflammation than ESR, the latter being influenced by a number of unrelated factors, such as age, sex, anemia, fibrinogen levels, hypergammaglobulinemia, and rheumatoid factor ${ }^{3}$. Third, CRP measurements are routinely used in clinical practice, and measurements can be standardized in a central laboratory for multicenter clinical trials.

The equations for DAS28-CRP with 3 and 4 variables were originally defined to "give good estimations of DAS28-ESR values on a group level"4. Currently, the same disease activity thresholds and the same cutoff points for European League Against Rheumatism response states originally derived for the DAS28-ESR are also applied for the DAS28-CRP.

Two key findings have emerged from the current literature. First, the DAS28-CRP has been validated with respect to functional and radiographic progression, with a validation profile similar to that based on ESR ${ }^{5}$. Second, subsequent data analyses from large cohort databases showed that DAS28-CRP and DAS28-ESR were well correlated, but a strong correlation does not necessarily mean the scores agree with each other ${ }^{5,6,7}$. In all studies, disease activity tended to be underestimated when DAS28-CRP was used $^{5,6,7,8}$. To increase the level of agreement between the 2 DAS28 formulations, one solution would be to derive a new set of cutoff points tailored for use with DAS28-CRP. The development of a robust approach leading to a set of cutoff points that can be generally applied across populations may prove difficult, as illustrated when the different cutoff points derived in different databases $6,7,8$ are applied to other datasets.

Another solution would be the modification of the definition/formula of the standard DAS28-CRP as proposed by Hensor, $e t a l^{9}$, and by Tamhane, et al in this issue of The Journal $^{10}$. Tamhane, et al analyzed the agreement between DAS28-ESR and DAS28-CRP using various new definitions and cutoffs suggested in the literature that had not been examined in any of the previous studies: both these new definitions of DAS28-CRP (Hensor's and Tamhane's) improved agreement and decreased underestimation, suggesting that a simple modification, without age-sex adjustment, in the conversion/multiplying factor with conventional cutoffs could be the optimal strategy to make the DAS28-ESR and DAS28-CRP equivalent. However, the concern is the generalizability of this transformation across different patient groups. It may be that the relationship between ESR and CRP differs among patients examined in different studies. ESR is well known to be affected by sex, age, immunoglobulin levels, rheumatoid factor, anemia, and more; whereas CRP is less affected by these factors. Therefore, the relationship between ESR and CRP might differ with various factors, such as age, the ratio of women to men, disease activity (which has an influence on anemia), and the ratio of patients with concomitant Sjögren syndrome, who often present hypergammaglobulinemia. It is interesting, but unclear, whether the

See Comparison of DAS vs ESR and CRP in African Americans with RA, page 1812

Personal non-commercial use only. The Journal of Rheumatology Copyright @ 2013. All rights reserved. 
ethnic background of patients also has an influence on this relationship. Previous studies that examined discordance between DAS28 by ESR versus CRP have been conducted predominantly on populations of Asians or European whites and data on African Americans/black Africans are lacking ${ }^{5,6,7,8}$. Differences in genetic polymorphisms that influence CRP levels exist. However, although CRP genotype may influence baseline CRP levels, in patients with very active disease, no such association was found ${ }^{11}$. It is interesting to note that results of Tamhane, et al in African American patients with RA were in accordance with other studies in Asiatic or white populations, with significant differences between DAS28-ESR and DAS28-CRP, albeit with high positive correlation. It is possible that a universal definition/formula ("one size fits all") may not be appropriate, and ethnicity- (or population)-specific formulae are needed. However, Hensor's DAS28-CRP formula developed in a white population improved agreement in these African American patients.

To extend the debate, if there is a large body of evidence supporting the benefit of tight control, less is known about which disease activity composite index should be used. Although there are differences in classification between these different disease activity composite indices and the American College of Rheumatology/European League Against Rheumatism remission definitions for RA, the associations with functional status and joint damage progression are highly comparable ${ }^{12}$. The choice of a composite index is dependent on its intended use and on personal preferences. The main limitation of the DAS28 is a broader definition of remission than with the other indices (and even more with DAS28-CRP) ${ }^{13}$. The need for a laboratory test (ESR or CRP) to obtain the DAS44, DAS28, and Simplified Disease Activity Index ${ }^{14}$ may limit the use of these indices in everyday practice. The clinical disease activity index, in contrast, can be obtained at any time and in any setting 15 .

The choice of a composite index is also dependent on the target. If the aim is remission, strict remission criteria carry a higher risk of overtreatment. However, a less strict definition may lead to residual disease activity and undertreatment. Randomized controlled trials directly comparing different definitions of remission or low disease activity using different disease activity composite indices as targets are needed.

DAS28-CRP and DAS28-ESR are not interchangeable: results of studies using DAS28-ESR and DAS28-CRP should not be compared, and for routine care, the same outcome should be used consistently. There is a need for an analysis plan involving regression-based models to obtain the most "universal" DAS28-CRP definition on large and diverse datasets.
CÉCILE GAUJOUX-VIALA, $\mathrm{MD}, \mathrm{PhD}$

Nîmes University Hospital,

Department of Rheumatology,

EA 2415, Montpellier I University,

Nîmes, France.

Address correspondence to Dr. Gaujoux-Viala;

E-mail: cecilegaujouxviala@yahoo.fr

\section{REFERENCES}

1. Prevoo ML, van 't Hof MA, Kuper HH, van Leeuwen MA, van de Putte LB, van Riel PL. Modified disease activity scores that include twenty-eight-joint counts. Development and validation in a prospective longitudinal study of patients with rheumatoid arthritis Arthritis Rheum 1995;38:44-8.

2. Van der Heijde DM, van 't Hof MA, van Riel PL, Theunisse LA, Lubberts EW, van Leeuwen MA, et al. Judging disease activity in clinical practice in rheumatoid arthritis: first step in the development of a disease activity score. Ann Rheum Dis 1990;49:916-20.

3. Van Leeuwen MA, van Rijswijk MH. Acute phase proteins in the monitoring of inflammatory disorders. Baillières Clin Rheumatol 1994;8:531-52.

4. Madsen OR. Is DAS28-CRP with three and four variables interchangeable in individual patients selected for biological treatment in daily clinical practice? Clin Rheumatol 2011; 30:1577-82.

5. Wells G, Becker J-C, Teng J, Dougados M, Schiff M, Smolen J, et al. Validation of the 28-joint Disease Activity Score (DAS28) and European League Against Rheumatism response criteria based on $\mathrm{C}$-reactive protein against disease progression in patients with rheumatoid arthritis, and comparison with the DAS28 based on erythrocyte sedimentation rate. Ann Rheum Dis 2009;68:954-60.

6. Inoue E, Yamanaka H, Hara M, Tomatsu T, Kamatani N Comparison of Disease Activity Score (DAS)28-erythrocyte sedimentation rate and DAS28- C-reactive protein threshold values. Ann Rheum Dis 2007:66:407-9.

7. Matsui T, Kuga Y, Kaneko A, Nishino J, Eto Y, Chiba N, et al. Disease Activity Score 28 (DAS28) using C-reactive protein underestimates disease activity and overestimates EULAR response criteria compared with DAS28 using erythrocyte sedimentation rate in a large observational cohort of rheumatoid arthritis patients in Japan. Ann Rheum Dis 2007;66:1221-6.

8. Castrejón I, Ortiz AM, García-Vicuña R, Lopez-Bote JP, Humbría

A, Carmona $\mathrm{L}$, et al. Are the $\mathrm{C}$-reactive protein values and erythrocyte sedimentation rate equivalent when estimating the 28-joint disease activity score in rheumatoid arthritis? Clin Exp Rheumatol 2008;26:769-75

9. Hensor EM, Emery P, Bingham SJ, Conaghan PG; YEAR Consortium. Discrepancies in categorizing rheumatoid arthritis patients by DAS-28(ESR) and DAS-28(CRP): can they be reduced? Rheumatology 2010;49:1521-9.

10. Tamhane A, Redden DT, McGwin G Jr, Brown EE, Westfall AO, Reynolds RJ IV, et al. Comparison of the disease activity score using erythrocyte sedimentation rate and $\mathrm{C}$-reactive protein in African Americans with rheumatoid arthritis. J Rheumatol 2013;40:1812-22.

11. Plant D, Ibrahim I, Lunt M, Eyre S, Flynn E, Hyrich KL, et al. Correlation of C-reactive protein haplotypes with serum C-reactive protein level and response to anti-tumor necrosis factor therapy in UK rheumatoid arthritis patients: results from the Biologics in Rheumatoid Arthritis Genetics and Genomics Study Syndicate cohort. Arthritis Res Ther 2012;14:R214.

12. Klarenbeek NB, Koevoets R, van der Heijde DM, Gerards AH, Ten Wolde S, Kerstens PJ, et al. Association with joint damage and 
physical functioning of nine composite indices and the 2011 ACR/EULAR remission criteria in rheumatoid arthritis. Ann Rheum Dis 2011;70:1815-21

13. Gaujoux-Viala C, Mouterde G, Baillet A, Claudepierre P, Fautrel B, Le Loët X, et al. Evaluating disease activity in rheumatoid arthritis: which composite index is best? A systematic literature analysis of studies comparing the psychometric properties of the DAS, DAS28, SDAI and CDAI. Joint Bone Spine 2012;79:149-55.
14. Smolen JS, Breedveld FC, Schiff MH, Kalden JR, Emery P, Eberl $\mathrm{G}$, et al. A simplified disease activity index for rheumatoid arthritis for use in clinical practice. Rheumatology 2003;42:244-57.

15. Aletaha D, Nell VP, Stamm T, Uffmann M, Pflugbeil S, Machold $\mathrm{K}$, et al. Acute phase reactants add little to composite disease activity indices for rheumatoid arthritis: validation of a clinical activity score. Arthritis Res Ther 2005;7:796-806.

J Rheumatol 2013;40:1785-7; doi:10.3899/jrheum.131042 